\title{
Papers
}

\section{Anti-HBs levels in infants of hepatitis B carrier mothers after delayed active immunization with recombinant vaccine concomitant with DTP-polio vaccine: is there need for a second dose of HBIg?}

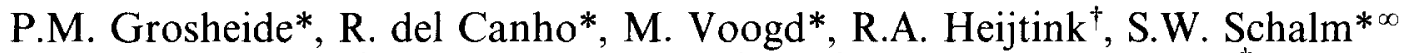
and the Dutch Study Group on Prevention of Neonatal Hepatitis $B^{\ddagger}$

The need for an additional dose of hepatitis $B$ immune globulin (HBIg) was studied by comparing infants receiving $1 \mathrm{ml} \mathrm{HBIg}$ at birth followed by hepatitis $B$ immunization, concomitant with DTP-polio vaccine, at 3, 4, 5 and 11 months (schedule E), with infants receiving the same schedule with additional HBIg at 3 months (schedule F). The immune response to recombinant hepatitis $B$ vaccine $(20 \mu \mathrm{g})$ was evaluated in 195 infants born to $H B s A g$-positive mothers allocated to groups $E$ and $F$ and compared with historic controls who received plasma vaccine $(10 \mu \mathrm{g})$ according to schedule $F$. Blood samples were drawn at $0,3,4,6,11,12$ and 24 months of age. No difference in efficacy between the two schedules was observed; 8 and $6 \%$ of infants born to HBeAg-positive HBsAg carrier mothers in groups $E$ and $F$, respectively, became $H B s A g$ carriers. Passively acquired antibodies at birth remained present for about 5 months in most infants. The seroprotection rates (anti-HBs $\geqslant 10 \mathrm{IU} \mathrm{I}^{-1}$ ) were over $90 \%$ at all time points and similar for groups $E$ and $F$. The titres of anti-HBs attained during the first 6 months were statistically lower $(\mathrm{p} \leqslant 0.02)$ for group $E$ than for group $F$ but similar thereafter. Anti-HBs titres in infants receiving the recombinant vaccine were significantly lower than in infants receiving the plasma vaccine $(\mathrm{p} \ll 0.001)$. Supplemental doses of HBIg in infants receiving a high dose of $\mathrm{HBIg}(>200 \mathrm{IU})$ at birth and the first dose of vaccine at the age of 3 months are not advised.
\end{abstract}

Keywords: Hepatitis B; neonate; hepatitis B immune globulin

In a large Dutch study a schedule of passive immunization starting within $2 \mathrm{~h}$ of birth and active immunization with plasma-derived vaccine at $3,4,5$ and

\footnotetext{
*Department of Internal Medicine II, University Hospital Dijkzigt, Dr Molewaterplein 40, 3015 GD Rotterdam, The Netherlands. 'Department of Virology, Erasmus University, Rotterdam, The Netherlands. ${ }^{\ddagger}$ Dutch Study Group: Ad S.M Nuijten, State School of Training for Midwives, John Zwijnenberg, Department of Pediatrics, Ruwaard van Putten Hospital, John R.J. Bänffer, Regional Public Health Laboratory, Yuriy W. Wladimiroff, Department of Obstetrics, Academic Hospital Dijkzigt, Marja Bakker-Bendik and Anneke Deurloo-Volaard, Rotterdam; Meindert J. Botman, Regional Laboratory of Pathology and Microbiology, Enschede; J. Adriaan Mazel and Harriet Ribbers-Smeenk, Borne; Gijsbert C. de Gast, Blood Transfusion Laboratory, Godelieve C.M.L. Christiaens, Department of Gynaecology and Obstetrics, Academic Hospital Utrecht, Leo J. Gerards and Hetty van Dijk, Wilhelmina Childrens Hospital, Utrecht; Willem P.F. Fetter and Willem Baerts, Department of Pediatrics, St Sophia Hospital (12), Zwolle, The Netherlands. ${ }^{\infty}$ To whom correspondence should be addressed. (Received 29 July 1993; revised 8 December 1993; accepted 9 December 1993)
}

11 months prevented significant hepatitis $B$ virus infection in infants of hepatitis B surface antigen (HBsAg) carrier mothers ${ }^{1-3}$. The delayed active hepatitis $B$ immunization, starting at 3 months of age concomitant with DTP-polio vaccine, had a similar protective efficacy as the generally recommended schedule of immunization starting immediately after birth $(0,1,2,11$ months) but gave rise to higher anti-HBs titres ${ }^{2,3}$. Infants on the delayed immunization schedule received a second dose of anti-HBs immune globulin ( $\mathrm{HBIg}$ ) at 3 months of age, and at the same time active immunization with the plasma-derived vaccine was started.

For practical and economic reasons, the simultaneous administration of DTP-polio vaccine and hepatitis B vaccine has been accepted in the Netherlands as the regimen of choice for the prevention of perinatal hepatitis B. However, in view of the levels of anti-HBs observed at 3 months of age, the need for the second dose of HBIg is uncertain ${ }^{2-4}$. Practical and economic reasons strongly favour the elimination of the HBIg injection at 3 months of age. The present study examines the anti-HBs levels in infants, born to $\mathrm{HBsAg}$-positive mothers, receiving a high dose of HBIg at birth and recombinant hepatitis $B$ 
vaccine at $3,4,5$ and 11 months, either with or without a second dose of HBIg at 3 months of age.

To confirm evidence that the immune response to the yeast-derived recombinant hepatitis B vaccine is similar to the response to the plasma-derived vaccine, we also compared the anti-HBs levels of infants receiving recombinant vaccine with the results found previously in infants using the same immunization regimens with the Merck plasma vaccine ${ }^{2,5}$

\section{PATIENTS AND METHODS}

\section{Procedure}

The study population consisted of healthy infants born to HBsAg-positive carrier mothers in three large city hospitals in Utrecht and Rotterdam and in one rural area providing prenatal and obstetric services. Entry to the study, which was approved by the medical ethics committees at each of the four participating centres, started on 1 January 1988 and ended on 1 October 1989. All pregnant women who attended the prenatal clinic at one of the participating centres were screened for the presence of HBsAg during their first visit. Pregnant women with a positive test result from the initial visit underwent a repeated test for $\mathrm{HBs} \mathrm{Ag}$ at delivery to verify the eligibility of infants for the study. Pregnant women who were positive for HBsAg were also tested for the presence of $\mathrm{HBeAg}$. At the prenatal visit following the diagnosis of HBsAg positivity, the mother was informed about the immunization study programme. Informed consent was obtained from the mother for the participation of her infant. Each infant received $1 \mathrm{ml}$ injection of HBIg intramuscularly within $2 \mathrm{~h}$ of birth. After referral to the paediatrician, infants in Rotterdam, were given $1 \mathrm{ml}$ of recombinant vaccine at $3,4,5$ and 11 months of age (group E). Infants born in Utrecht and the rural area were assigned to group $F$ and were given the same schedule as infants in group E, but received an additional dose of $1 \mathrm{ml} \mathrm{HBIg}$ at 3 months of age. The parent or guardian was asked to record any local or systemic reaction for 5 days after each vaccine injection.

Immediately after delivery cord blood was obtained after cleansing of the umbilical cord. Follow-up blood samples were taken at 3, 4,6 and 11 months and at the ages of 1 and 2 years (Figure 1 ).

Infants of HBsAg-positive mothers on the same schedule of passive-active immunization as the infants in group $\mathrm{F}$, but who received $10 \mu \mathrm{g}$ of the plasma-derived vaccine (HBvax; Merck, Sharp \& Dohme, $20 \mu \mathrm{g} \mathrm{ml}^{-1}$ ) served as historic controls. Results of the study on the protective efficacy and immunogenicity of the plasmaderived hepatitis B vaccine in infants of $\mathrm{HBs} A g$-positive mothers have been reported previously ${ }^{1-3}$.

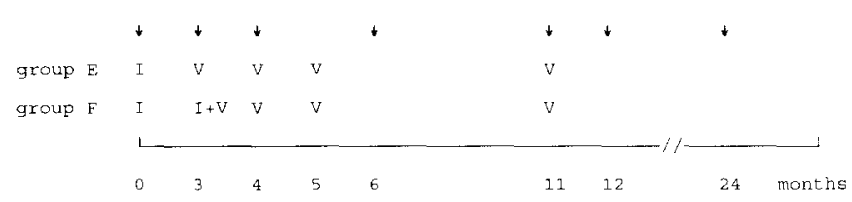

Figure 1 Passive-active immunization schedule: I, HBIg administered (200 IU anti-HBs $\left.\mathrm{ml}^{-1}\right)$; V, vaccine administered ( $20 \mu \mathrm{g}$ Engerix-B ml $\left.{ }^{-1}\right)$ $\downarrow$, blood sample taken (historic controls received $10 \mu \mathrm{g}$ plasma vaccine (HBvax) according to schedule F)

\section{Laboratory tests}

All serum samples obtained from mothers during the course of the study were tested for $\mathrm{HBsAg}$ and $\mathrm{HBeAg}$ by radioimmunoassay (Abbott Laboratories, Chicago, IL, USA). Serum samples from infants were assayed for anti-HBs by radioimmunoassay (Abbott). The results were expressed in international units per litre $\left(\mathrm{IU} \mathrm{I}^{-1}\right)$. Blood samples obtained at 12 and 24 months of age were also assayed for anti-HBc, and for $\mathrm{HBsAg}$ in cases where

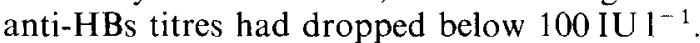

\section{Hepatitis B immune globulin}

Hepatitis B immune globulin was prepared by the Central Laboratory of the Netherlands Red Cross Blood Transfusion Service, Amsterdam. The HBIg was supplied in vials of $1 \mathrm{ml}$ and stored at $2-8^{\circ} \mathrm{C}$. The full dose of HBIg, $1 \mathrm{ml}$ containing 200 to $250 \mathrm{IU}$ anti-HBs, was given intramuscularly in the anterolateral region of the thigh.

\section{Vaccine}

The recombinant hepatitis $\mathrm{B}$ vaccine, alum adsorbed, prepared by SmithKline Biologicals, Rixensart, Belgium, was used. The vaccine was stored at $2-8^{\circ} \mathrm{C}$. The vaccine dose of $1 \mathrm{ml}(20 \mu \mathrm{g})$ was given intramuscularly in the anterolateral part of the other thigh in cases of concomitant injection of $\mathrm{HBIg}$.

\section{Statistics}

The degree of simlarity between the two treatment groups was demonstrated by comparing baseline characteristics (e.g. parity, age) of the HBsAg-positive mothers. Differences in proportions were compared using the $\chi^{2}$ test and Fisher's exact test. Median ages of mothers were compared using the Wilcoxon test. Differences in anti-HBs seroconversion rates between treatment groups were calculated using the Fisher's exact test and 95\% confidence intervals $(95 \% \mathrm{CI})$. The exact values for $95 \%$ $\mathrm{CI}$ are given in Geigy Scientific Tables ${ }^{6}$. The geometric mean titres (GMTs) were calculated only for those infants who had anti-HBs $\geqslant 10 \mathrm{IU}^{-1}$. Anti-HBs levels were compared using the Wilcoxon rank sum test. The Wilcoxon-Mann-Whitney test was used to compare the median immunization intervals between groups.

\section{RESULTS}

\section{Participants}

During the study period 210 infants were born to the mothers who had agreed to participate in the study. Nine infants were withdrawn from the trial by their parents before the treatment had started. Thus 201 infants entered the study, of whom six infants, three in each group, were excluded from the final analysis because they received an incorrect vaccination schedule. In all six infants the last available blood sample tested was negative for $\mathrm{HBsAg}$.

Results for the 195 infants who were studied for at least 6 months are presented; 102 were on schedule $E$ and 93 on schedule F. In Table 1 comparisons between treatment groups are presented.

In both groups $97 \%$ of infants received HBIg at birth and all injections: 99 infants in group $E$ and 90 infants in group F. Blood samples at 12 and 24 months of age were taken from 88 and $86 \%$ of infants in group $\mathrm{E}$ and 74 and $73 \%$ of infants in group F, respectively. 


\section{Anti-HBs response}

The distribution of the anti-HBs titres of infants during the 2 years of follow-up is shown in Table 2. The seroconversion rates (anti-HBs $\geqslant 10 \mathrm{IU}^{-1}$ ) were similar for both groups at all months studied: more than $92 \%$ at all times and above $97 \%$ from month 6 onwards. The geometric mean antibody titres of vaccinees with anti-HBs $\geqslant 10{\mathrm{IU} 1^{-1}}$ were significantly higher for treatment group $\mathrm{F}$ at months 3,4 and 6 . These differences were no longer significant at 11, 12 and 24 months of age.

\section{Recombinant vaccine compared with plasma vaccine}

A comparison of infants on schedule $\mathrm{F}$ and the historic controls receiving the same vaccination regimen with the plasma vaccine is presented in Table 3. The percentage of infants seroconverting for anti-HBs was similar for

Table 1 Comparison of the characteristics between study groups

\begin{tabular}{|c|c|c|c|}
\hline Mothers & $\begin{array}{l}\text { Schedule } E \\
(n=102)\end{array}$ & $\begin{array}{l}\text { Schedule F } \\
(n=93)\end{array}$ & $p$ value \\
\hline Median age (years) & $26(18-38)^{a}$ & $27(18-40)$ & $0.86^{b}$ \\
\hline HBeAg-positive, no. (\%) & $13(13)$ & $17(18)$ & $0.28^{c}$ \\
\hline Primigravidae, no. (\%) & $36(35)$ & $26(28)$ & $0.27^{c}$ \\
\hline Country of birth, no. (\%) & & & $0.002^{C}$ \\
\hline Netherlands + other & $27(26)$ & $12(13)$ & \\
\hline Mediterranean & $48(47)$ & $64(69)$ & \\
\hline Surinam & $14(14)$ & $3(3)$ & \\
\hline Asia & $13(13)$ & $14(15)$ & \\
\hline
\end{tabular}

a Numbers in parentheses indicate 5th to 95th percentiles

${ }^{b}$ Wilcoxon test

${ }^{c} \chi^{2}$ test both vaccines. Significantly higher GMTs were obtained with the plasma vaccine than with the recombinant vaccine, both after the initial series of vaccination at month 6 and during follow-up.

\section{HBV infections}

Despite passive-active immunization $1 \%(2 / 195)$ of infants, one in each group, became $\mathrm{HBsAg}$-positive and developed the HBV carrier state. Both infants had HBeAg-positive HBsAg carrier mothers with high levels of HBV DNA $\left(223 \mathrm{pg} \mathrm{ml}^{-1}\right.$ and $193 \mathrm{pg} \mathrm{ml}^{-1}$ by Abbott HBV DNA assay) and had detectable HBsAg before the age of 4 months. The HBsAg carrier rates among infants born to HBsAg- and HBeAg-positive mothers were $8 \%$ (95\% CI: $0.19-36.03)$ and 6\% (95\% CI: $0.15-28.69)$ in groups $\mathrm{E}$ and $\mathrm{F}$, respectively. At 12 months of age, $18 \%$ of infants $(18 / 98)$ on schedule $\mathrm{E}$ compared with $20 \%$ of infants $(14 / 70)$ on schedule $F$ were anti-HBc-positive. At the age of 24 months seven infants, including the two infants who were HBsAg-positive, tested anti-HBcpositive. The total number of $\mathrm{HBV}$ infections was similar for both groups: three $(3 \%)$ of 102 infants in group $E$ (95\% CI: $0.62-8.77)$ and four (4\%) of 93 infants in group F (95\% CI: $1.18-10.65)$. The inapparent HBV infections at 24 months of age (anti-HBc-positive only) were observed both in infants born to HBsAg- and $\mathrm{HBeAg}$-positive mothers and in infants born to HBeAg-negative mothers.

\section{Vaccination interval}

The median ages at which infants were given the first dose of vaccine are given in Table 4. For some

Table 2 Anti-HBs levels in infants of HBsAg-positive mothers who responded to passive-active immunization according to schedule $E$ or $F$

\begin{tabular}{|c|c|c|c|c|c|c|c|c|c|c|}
\hline \multirow[b]{3}{*}{ Month } & \multicolumn{5}{|c|}{ Anti-HBs seroconversion $\left(\geqslant 10 \mathrm{IU} \mathrm{I}^{-1}\right)$} & \multicolumn{5}{|c|}{ Anti-HBs levels $\left(\left.I U\right|^{-1}\right)$} \\
\hline & \multicolumn{2}{|c|}{ Schedule E } & \multicolumn{2}{|c|}{ Schedule F } & \multirow[b]{2}{*}{$p$ value ${ }^{a}$} & \multicolumn{2}{|c|}{ Schedule E } & \multicolumn{2}{|c|}{ Schedule F } & \multirow[b]{2}{*}{$p$ value ${ }^{b}$} \\
\hline & $n$ & $(\%)$ & $n$ & $(\%)$ & & GMT & ( \pm 2 s.e.m.) & GMT & ( \pm 2 s.e.m.) & \\
\hline 3 & $90 / 94$ & (96) & $67 / 73$ & (92) & NS & 40 & $(36-44)$ & 58 & $(48-71)$ & $\ll 0.001$ \\
\hline 4 & $82 / 89$ & (92) & $74 / 75$ & (99) & NS & 25 & $(21-29)$ & 148 & $(124-176)$ & $\ll 0.001$ \\
\hline 6 & $89 / 91$ & (98) & $74 / 76$ & (97) & NS & 374 & $(264-530)$ & 733 & $(507-1060)$ & 0.02 \\
\hline 11 & $90 / 91$ & (99) & $64 / 65$ & (98) & NS & 746 & $(567-981)$ & 1126 & $(776-1636)$ & NS \\
\hline 12 & $89 / 90$ & (99) & $68 / 69$ & (99) & NS & 9317 & $(6558-13237)$ & 9699 & $(6475-14528)$ & NS \\
\hline 24 & $85 / 88$ & (97) & $67 / 68$ & (99) & NS & 1727 & $(1216-2452)$ & 1125 & $(767-1649)$ & NS \\
\hline
\end{tabular}

NS, not significant

${ }^{a}$ Fisher's exact test

bilcoxon rank sum test

Table 3 Anti-HBs levels in infants of HBsAg-positive mothers after administration of plasma vaccine (historic controls) or recombinant hepatitis B vaccine (group F)

\begin{tabular}{|c|c|c|c|c|c|c|c|c|c|c|}
\hline \multirow[b]{3}{*}{ Month } & \multicolumn{5}{|c|}{ Anti-HBs seroconversion } & \multicolumn{5}{|c|}{ Anti-HBs levels $\left(|\mathrm{U}|^{-1}\right)$} \\
\hline & \multicolumn{2}{|c|}{ Plasma } & \multicolumn{2}{|c|}{ Recombinant } & \multirow[b]{2}{*}{$\rho$ value ${ }^{a}$} & \multicolumn{2}{|c|}{ Plasma } & \multicolumn{2}{|c|}{ Recombinant } & \multirow[b]{2}{*}{$\rho$ value $^{b}$} \\
\hline & $n$ & $(\%)$ & $n$ & $(\%)$ & & GMT & $( \pm 2$ s.e.m. $)$ & GMT & ( \pm 2 s.e.m. $)$ & \\
\hline 3 & $94 / 99$ & (95) & $67 / 73$ & $(92)$ & NS & 32 & $(29-37)$ & 58 & $(48-71)$ & $\ll 0.001$ \\
\hline 6 & $105 / 107$ & (98) & $74 / 76$ & (97) & NS & 1120 & $(812-1545)$ & 733 & $(507-1060)$ & $\ll 0.001$ \\
\hline 11 & $95 / 98$ & (97) & $64 / 65$ & (98) & NS & 2360 & $(1832-3041)$ & 1126 & $(776-1636)$ & $\ll 0.001$ \\
\hline 12 & $95 / 99$ & (96) & $68 / 69$ & (99) & NS & 15739 & $(11738-21104)$ & 9699 & $(6475-14528)$ & $\ll 0.001$ \\
\hline 24 & $87 / 91$ & (96) & $67 / 68$ & (99) & NS & 1728 & $(1284-2325)$ & 1125 & $(767-1649)$ & $\ll 0.001$ \\
\hline
\end{tabular}

NS, not significant

aFisher's exact test

${ }^{b}$ Wilcoxon rank sum test 
Table 4 Length of time (days) between birth and the administration of the first dose of hepatitis $B$ vaccine to infants on schedule $E$ or $F$

\begin{tabular}{lcll}
\hline First dose of vaccine & Schedule E & Schedule F & $p$ value \\
\hline Infants (no.) & 102 & 93 & \\
Target age (days) & 91 & 91 & \\
Median age (days) & 96 & 94 & $0.12^{a}$ \\
Mean age (s.d.) & $100(16)$ & $99(17)$ & \\
5th to 95th percentiles & $84-125$ & $83-148$ & \\
\hline
\end{tabular}

aWilcoxon-Mann-Whitney test

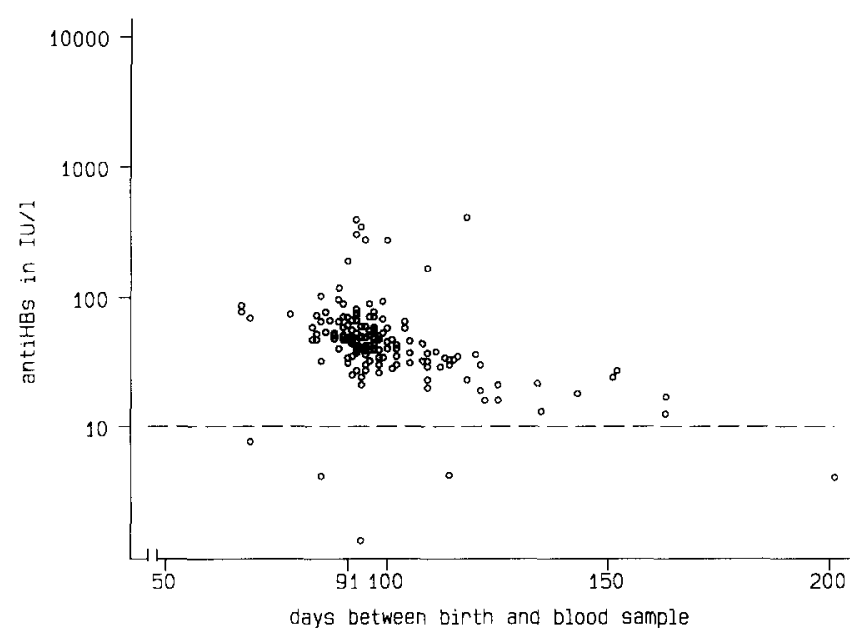

Figure 2 The effect of time on the passively acquired anti-HBs levels between birth and the first dose of vaccine (target age 91 days). Anti-HBs titres $\geqslant 1 \mathrm{IU}^{-1}$ are shown

infants, the 0 to 3 month interval was extremely long. For instance, $21 \%$ of infants on schedule E (21/99) and $20 \%$ of infants $(18 / 90)$ on schedule $F$ received their injection at month 3 more than 2 weeks later than the target age ( 91 days).

Figure 2 illustrates the relationship between the time at which the month 3 blood sample was taken (target age 91 days) and the level of anti-HBs acquired passively at birth. As the 0 to 3 month interval increased, the antibody level decreased significantly $(p<0.001)$. From Figure 2 it can also be deduced that the passively acquired antibodies last approximately 5 months in most infants before falling below the critical level of $10 \mathrm{IU}^{-1}$. Ten infants, however, had no protective levels of anti-HBs at 3 months of age. Five infants had less than $10 \mathrm{IU}^{-1}$ anti-HBs and the other five infants had no detectable anti-HBs. Only two of these infants, one in each group, received their first dose beyond the mean age of vaccine administration plus the standard deviation. Except for the one infant who became an HBsAg carrier, all infants with anti-HBs $<10 \mathrm{IU}^{-1}$ at 3 months of age were born to $\mathrm{HBeAg}$-negative mothers and developed a protective immune response from month 6 onwards.

\section{DISCUSSION}

We examined the need for an additional HBIg dose at 3 months of age in infants receiving a high dose of HBIg at birth and simultaneous injections of hepatitis $B$ vaccine and DTP-polio vaccine at 3, 4,5 and 11 months of age. The rates of seroprotection (anti-HBs $\geqslant 10 \mathrm{IU} \mathrm{l}^{-1}$ ) in group E, without the additional dose of $\mathrm{HBIg}$, and group
F were similar in all cases. No significant benefit from the additional HBIg dose at 3 months was observed, especially during the first 6 months of life when the effect of $\mathrm{HBIg}$ given at birth is waning?

More importantly, we found no differences in the number of infants who became $\mathrm{HBsAg}$-positive in group $\mathrm{E}(8 \%)$ and group $\mathrm{F}(6 \%)$, whereas the number of infants born to $\mathrm{HBsAg}$ - and $\mathrm{HBeAg}$-positive mothers was similar in both groups (Table I). Although the 95\% CI for the difference between the two population proportions range from $-16 \%$ to $20 \%$, showing the relative imprecision due to the limited sample size, these percentages are comparable to the number of $\mathrm{HBsAg-positive} \mathrm{infections}$ (8\%; 95\% CI: $1.7-21.9)$ observed in the larger group of historic controls who received two doses of HBIg at 0 and 3 months and the plasma-derived vaccine at $3,4,5$ and 11 months of $\mathrm{age}^{3}$. The percentage of infants on schedule $E$ or $F$ with inapparent $\mathrm{HBV}$ infection (anti-HBc-positive only) was also similar for both groups. After a high dose of $\mathrm{HBIg}$ given at birth, antibodies tend to remain above the critical level of $10 \mathrm{IU}^{-1}$ anti-HBs for approximately 5 months (Figure 2).

The immune response provided by vaccination initiated at 3 months of age is rapid and strong ${ }^{2.8-10}$, resulting in similar protective efficacy $(98 \%$ versus $90-93 \%)$ compared with vaccination starting at birth ${ }^{2,8}$. Our study results of excellent protective efficacy after delayed active immunization support the findings by Beasley et $a l^{8}$.

Ten infants had no protective levels of anti-HBs at 3 months of age. All infants but one were born to HBeAg-negative mothers and the reasons for the absence of anti-HBs levels $\geqslant 10 \mathrm{IU}^{-1}$ are not clear. The low levels of anti-HBs in these infants may have been caused either by failures in the administration of $\mathrm{HBIg}$ or by consumption of the passively administered anti-HBs antibodies. For programmes with delayed active immunization, monitoring of $\mathrm{HBIg}$ administration is indicated. In addition, we advocate the use of $1 \mathrm{ml}$ of HBIg instead of the usually recommended dose of $0.5 \mathrm{ml}$.

The practical consequences of our findings are that a schedule with high efficacy and compliance at relatively low cost can be implemented in the Dutch childcare system to prevent perinatal infections in infants of HBsAg-positive mothers, provided that administration of hepatitis $B$ vaccine in clinical practice is timely.

The data from this study further demonstrate that the recombinant hepatitis $\mathrm{B}$ vaccine is efficacious in inducing high antibody levels in infants of $\mathrm{HBsAg-positive}$ mothers. Although we, like others ${ }^{5}$, found that the recombinant vaccine and plasma vaccine are equally immunogenic in inducing levels of anti-HBs $\geqslant 10 \mathrm{IU}^{-1}$ the GMTs of anti-HBs antibodies in infants given the recombinant vaccine were significantly lower than those observed with plasma vaccine. Others have also demonstrated that the recombinant vaccine $(10 \mu \mathrm{g}$ or $20 \mu \mathrm{g}$ Engerix-B) produces a relatively lower antibody titre than the plasma vaccine $(10 \mu \mathrm{g}$ or $20 \mu \mathrm{g}$ HBvax, MSD $)^{11.12}$. Differences in GMTs between the current recombinant vaccine study and our previous study using the plasma vaccine require careful interpretation. Even though the vaccination regime and methods of testing (radioimmunoassay, Ausab, Abbott) were similar, the vaccine doses were different and the study populations might have changed over time. It should also be noted 
that antibodies were assayed with kits containing plasma-derived $\mathrm{HBsAg}$ as the antigen. Conceivably, antibodies induced by recombinant-derived $\mathrm{HBsAg}$ may be only partially homologous to the plasma-derived $\mathrm{HBsAg}{ }^{13}$. The higher geometric mean titres in group $\mathrm{F}$ during the first 6 months are probably the result of the passively acquired antibodies, since simultaneous administration of HBIg and vaccine was not found to either reduce or stimulate the immune response ${ }^{14}$.

The possibility of giving reduced doses of vaccine to lower the cost has been evaluated by Lee et $a .^{15}$. As the protective efficacy decreased with the dose of antigen given, the authors recommended that lower doses of vaccine should not be used for infants of carrier mothers. Since a rapid and strong immune response to the vaccine may enhance optimal early protection and long-lasting immunity, we support the recommendation of the Dutch Health Authorities to use the adult dose of the recombinant vaccine.

The recommendations on $\mathrm{HBIg}$ and hepatitis B vaccine apply only for developed countries where maternal screening for HBsAg and passive-active immunization in infants of $\mathrm{HBsAg}$-positive women is the standard policy for the prevention of perinatal hepatitis $B$ infection. In the Netherlands, where many home deliveries take place, HBIg should be given at birth by the person assisting in the delivery. The dose should be adequate to maintain protection until the age of 3 months when hepatitis B vaccination in infants is started at the same time as DTP-polio vaccination at the Child Health Clinics.

\section{ACKNOWLEDGEMENTS}

This study is generously funded by a grant from the Praeventiefonds, The Netherlands (no. 28-760-2). The authors thank J. Boot and W.C.J. Hop for their technical assistance and statistical advice, and the members of the Virology Department, Erasmus University, Rotterdam, The Netherlands for their support.

\section{REFERENCES}

1 Mazel, J.A., Schalm, S.W., de Gast, G.C., Nuijten, A.S.M., Heijtink, R.A., Botman, M.J. et al. Passive-active immunization in neonates of HBsAg-positive carrier mothers: preliminary observations. $B M J$ 1984, 288, 513-515

2 Schalm, S.W., Mazel, J.A., de Gast, G.C., Heijtink, R.A., Botman, M.J., Bänffer, J.R.J. ot al. Prevention of hepatitis B injection in newborns through mass screening and delayed vaccination of all infants of mothers with hepatitis B surface antigen. Pediatrics 1989, 83, 1041-1048

3 Grosheide, P.M., del Canho, R., Heijtink, R.A., Nuijten, A.S.M., Zwijnenberg, J., Bänffer, J.R.J. et al. Passive-active immunization in infants of hepatitis $B$ e antigen-positive mothers: comparison of the efficacy of early and delayed active immunization. Am. J. Dis. Child. 1993, 147, 1316-1320

4 Beasley, R.P., Hwang, L.Y., Stevens, C.E., Lin, C.C., Hsieh, F.J., Wang, K.Y. et al. Efficacy of hepatitis B immune globulin for prevention of perinatal transmission of the hepatitis $B$ virus carrier state: final report of a randomized double-blind placebo-controlled trial. Hepatology 1983, 3, 135-141

5 Cadranel, S., Zeghlache, S., Fernandez, S., Safary, A. and Andre, F.E. Vaccination of newborns of $\mathrm{HBsAg}$ positive carrier mothers with a recombinant DNA hepatitis $B$ vaccine. Postgrad. Med. J. 1987, 63 (Suppl 2), 159-160

6 Lenter, C. (Ed). Geigy Scientific Tables 8th edn, Geigy, Basel, Switzerland, 1982, pp. 89-102

7 Beasley, R.P. and Hwang, L.L. Postnatal infectivity of hepatitis B surface antigen-carrier mothers. J. Infect. Dis. 1983, 147, 185-190

8 Beasley, R.P., Hwang, L.-Y., Lee, G.C.-H., Lan, C.-C., Roan, C.-H. Huang, F.-Y. and Chen, C.-L. Prevention of perinatally transmitted hepatitis $B$ virus infections with hepatitis $B$ immune globulin and hepatitis B vaccine. Lancet 1983, ii, 1099-1102

9 Piazza, M., Picciotto, L., Villari, R., Guadagnino, V., Orlando, R. Isabella, $L$. et al. Hepatitis $B$ immunization with a reduced number of doses in newborn babies and children. Lancet 1985, i, 949-951

10 Piazza, M., Picciotto, L., Villari, R., Guadagnino, V., Orlando, R., Macchia, $V$. et al. Two-dose hepatitis $B$ immunisation regimen for infants. Lancet 1985, ii, 1120-1121

11 Panda, S.K., Ramesh, R., Rao, K.V.S., Gupta, A., Zuckerman, A.J. and Nayak, N.C. Comparative evaluation of the immunogenicity of yeast-derived (recombinant) and plasma-derived hepatitis $B$ vaccine in infants. J. Med. Virol. 1991, 35, 297-302

12 Payton, C.D., Scarisbrick, D.A. Sikotra, S. and Flower, A.J.E Vaccination against hepatitis B: comparison of intradermal and intramuscular administration of plasma derived and recombinant vaccines. Epidemiol. Infect. 1993, 110, 177-180

13 McCartney, R.A., Harbour, J., Roome, A.P.C.H. and Caul, E.O. Comparison of enhanced chemiluminescence and microparticle enzyme immunoassay for the measurement of hepatitis B surface antibody. Vaccine 1993, 11, 941-945

14 Lelie, P.N., Reesink, H.W., Grijm, R., de Jong-van Manen, S.Th. and Reerink-Brongers, E.E. Simultaneous passive and active immunization against hepatitis $B$; non-interference of hepatitis $B$ immune globulin with the anti-HBs response to reduced doses of heat-inactivated hepatitis B vaccine. Hepatology 1986, 6, 971-975

15 Lee, C.Y., Hwang, L.Y. and Beasley, R.P. Low-dose hepatitis B vaccine. Lancet 1989 , ii, $860-861$ 